\title{
DIVERSIDADE, DISTRIBUIÇÃO ESPACIAL E TEMPORAL DE ANFÍBIOS ANUROS (AMPHIBIA, ANURA) NA REGIÃO NOROESTE DO ESTADO DE SÃO PAULO, BRASIL
}

\author{
Tiago da Silveira Vasconcelos ${ }^{1}$, Denise de C. Rossa-Feres ${ }^{2}$
}

Biota Neotropica v5 (n2) - http://www.biotaneotropica.org.br/v5n2/pt/abstract?article+BN01705022005

Recebido em 10/03/2005.

Versão reformulada recebida em 04/05/05

Publicado em 03/08/05

\author{
${ }^{1}$ Programa de Pós-Graduação em Biologia Animal, UNESP, campus de São José do Rio Preto, São Paulo, Brasil \\ (www.ibilce.unesp.br). Rua Cristóvão Colombo, 2265, Departamento de Zoologia e Botânica, Laboratório de Ecologia \\ Animal. CEP: 15054-000. email:zoologia@ig.com.br \\ ${ }^{2}$ Departamento de Zoologia e Botânica, UNESP, campus de São José do Rio Preto, SP. email: denise@ibilce.unesp.br
}

\begin{abstract}
The richness and abundance of adults and tadpoles of anuran amphibians were studied during 15 months in ten water bodies, in Nova Itapirema, São Paulo, Brazil, region that was intensively impacted by agricultural activities. Twenty-seven species of anurans were registered, and among them four species were new records for this region. Most species are typical from open areas, and the higher richness and species diversity were found in lentic water bodies. However, due to the few water bodies in fragments of riparian forest, comparisons among water bodies in open area and in fragments of riparian forest were not possible. Six descriptors of water bodies heterogeneity were determined, but no one was related with the species richness. On the other hand, both richness and abundance of species were strongly correlated with climatic variables. The species composition ( $\beta$ diversity) was similar among the water bodies, which probably reflect the great niche breadth, typical of species from unstable or modified environments. The anuran richness observed in the studied region is similar to other localities where the level of environmental conservation is higher, as the Estação Ecológica de Águas Emendadas (Federal District) and the Floresta Nacional de Silvânia (Goiás).
\end{abstract}

Key Words: Agroecosystem, community ecology, resource partitioning, tadpoles.

\section{Resumo}

A riqueza e a abundância de adultos e girinos de anuros foram estudadas ao longo de 15 meses em dez corpos de água no noroeste do estado de São Paulo, região intensamente antropizada pela conversão de hábitats naturais em terras agrícolas. Foram registradas 27 espécies de anfíbios anuros, das quais quatro espécies constituem novos registros para a região. A maioria das espécies é característica de ambientes de formação vegetal aberta, sendo as maiores riqueza e diversidade de espécies encontradas em corpos de água lênticos em área aberta. Entretanto, em conseqüência do pequeno número de corpos de água encontrados nos fragmentos de mata da região, não é possível comparar a ocorrência de anuros em áreas abertas e fechadas. Foram determinados seis descritores da heterogeneidade dos corpos d'água, e nenhum deles foi relacionado com a riqueza de espécies. Por outro lado, tanto a riqueza quanto a abundância das espécies foram fortemente correlacionadas com as variáveis climáticas. A composição de espécies (diversidade $\beta$ ) variou pouco entre os corpos d'água, como provável conseqüência da grande amplitude de nicho, comum em espécies que ocupam ambientes instáveis ou alterados pelo homem, como os presentemente estudados. A riqueza de espécies da área amostrada é relativamente alta, quando comparada a outras localidades onde o grau de conservação ambiental é superior, como na Estação Ecológica de Águas Emendadas (Distrito Federal) e Floresta Nacional de Silvânia (Goiás).

Palavras -chave: Agro-ecossistema, ecologia de comunidades, partilha de recursos, girinos.. 


\section{INTRODUÇÃO}

Atualmente são conhecidas no mundo cerca de 5067 espécies de anfíbios anuros (IUCN 2004), sendo a maior riqueza encontrada na região neotropical (Duellman 1988). O Brasil abriga a maior riqueza de anuros do planeta, com 747 espécies registradas até o momento (SBH 2005), e uma taxa de endemismo de 64\% (IUCN 2004). No estado de São Paulo estão registradas mais de 180 espécies de anuros (Haddad 1998), o que corresponde a $24 \%$ da diversidade brasileira e 3,5\% da diversidade mundial. Entretanto, informações sobre história natural ainda são desconhecidas para a maioria das espécies brasileiras (Haddad \& Sazima 1992, Haddad 1998).

A maioria dos estudos com anfíbios anuros no Brasil foi desenvolvida ao longo do litoral ou de grandes rios (Brandão \& Araújo 1998), enquanto comunidades interioranas têm sido estudadas apenas recentemente (p.ex., Rossa-Feres \& Jim 2001, Bastos et al. 2003, Toledo et al. 2003). A região noroeste do estado de São Paulo apresenta clima sazonal, com pronunciada estação seca, e os maiores índices de conversão de hábitats naturais em terras agrícolas do estado (IPT 2000). Apesar disso, e dos poucos inventários realizados, 28 espécies de anuros estão registradas nessa região (Vizotto 1967, Cais 1992, Bernarde \& Kokubum 1999, Rossa-Feres \& Jim 2001) e os padrões de diversidade, uso de hábitat e distribuição dessas espécies ainda são pouco conhecidos.
Os objetivos deste estudo são descrever a distribuição espacial e temporal e a diversidade de anuros em uma localidade (Nova Itapirema) na região noroeste do estado de São Paulo, Brasil, e determinar quais tipos de corpos de água sustentam maior diversidade e possibilitam maior sucesso reprodutivo, determinado pela presença de girinos.

\section{MATERIAL E MÉTODOS}

\section{Área e corpos d’água estudados}

Este estudo foi desenvolvido em Nova Itapirema

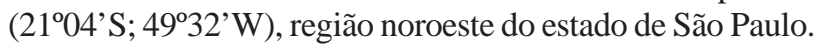
Segundo dados da Divisão Regional Agrícola (DIRA) de São José do Rio Preto, o clima desta região é do tipo Cwa-Aw de Köppen, caracterizado por uma estação quente e úmida no verão e estiagem no inverno. A estação chuvosa (setembro a março) tem início variável ano a ano (Rossa-Feres \& Jim 2001) e recebe $85 \%$ da precipitação pluviométrica anual, enquanto a estação fria e seca (abril a agosto) recebe apenas 15\% da precipitação pluviométrica anual, que varia de 1100 a $1250 \mathrm{~mm}$ ( $\pm 225 \mathrm{~mm}$ ) (Barcha \& Arid 1971). A vegetação original desta região, composta por Floresta Estacional Semidecidual e manchas de Cerrado (Ab’Sáber 2003), foi intensamente devastada em função do solo propício à agricultura, restando pequenos fragmentos espalhados em sua área de ocorrência natural (São Paulo 2000).

Tabela I: Principais características dos dez corpos d’água estudados em Nova Itapirema, São Paulo. AP1 = Açude Permanente 1; AP2 = Represa Permanente; AP3 = Açude Permanente 3; AP4 = Lagoa Permanente; AT1 = Açude Temporário 1; AT2 = Açude Temporário 2; BT = Brejo Temporário em área aberta; $B P=$ Brejo Permanente em mata ciliar; $C A=$ Córrego em área aberta; CM = Córrego em mata ciliar. $A B=$ Arbustos (p.ex., Melastomataceae, Piperaceae, Solanaceae); $M=$ macrófitas (Cyperaceae, Nympheaceae, Pontederiaceae); SN = Solo $\mathrm{Nu} ; \mathrm{T}=$ Taboa (Thyphaceae); VHE = Vegetação Herbácea Ereta (p.ex., Asteraceae, Cyperaceae, Malvaceae, Onagraceae, Poaceae, Pteridophyta); VHR = Vegetação Herbácea Rasteira (Poaceae). A seqüência dos tipos de vegetação nos itens "Vegetação no Interior" e "Vegetação Marginal” indica sua predominância decrescente.

\begin{tabular}{|c|c|c|c|c|c|c|}
\hline & $\begin{array}{c}\text { Coordenadas } \\
\text { geográficas }\end{array}$ & Duração & $\begin{array}{l}\text { Área } \\
\left(\mathrm{m}^{2}\right)\end{array}$ & $\begin{array}{l}\text { Profundidade } \\
\text { (m) }\end{array}$ & $\begin{array}{l}\text { Vegetação } \\
\text { no interior }\end{array}$ & Vegetação marginal \\
\hline AP1 & $\begin{array}{l}21^{\circ} 04^{\prime} 41^{\prime \prime \prime} \mathrm{S} ; \\
49^{\circ} 32^{\prime} 20^{\prime \prime \prime} \mathrm{W}\end{array}$ & Permanente & 580 & 0,7 & $\mathrm{~T}, \mathrm{M}, \mathrm{VHE}$ & VHR, VHE, AB \\
\hline AP2 & $\begin{array}{l}21^{\circ} 04^{\prime} 33^{\prime \prime}, \mathrm{S} ; \\
49^{\circ} 32^{\prime} 21^{\prime \prime} \mathrm{W}\end{array}$ & Permanente & 300 & 0,7 & $\mathrm{M}, \mathrm{T}, \mathrm{VHE}$ & VHR, VHE \\
\hline AP3 & $\begin{array}{l}21^{\circ} 04^{\prime} 52^{\prime \prime}, \mathrm{S} ; \\
49^{\circ} 31^{\prime} 09^{\prime,} \mathrm{W}\end{array}$ & Permanente & 166,4 & 0,65 & VHE & SN, VHR, VHE, AB \\
\hline AP4 & $\begin{array}{l}21^{\circ} 04^{\prime} 25^{\prime \prime}, \mathrm{S} ; \\
49^{\circ} 31^{\prime} 08^{\prime}, \mathrm{W}\end{array}$ & Permanente & 800 & 1,5 & VHE & VHR, VHE, SN, AB \\
\hline AT1 & $\begin{array}{l}21^{\circ} 04^{\prime} 40^{\prime \prime}, \mathrm{S} ; \\
49^{\circ} 32^{\prime} 23^{\prime \prime} \mathrm{W}\end{array}$ & Temporário & 704 & 0,7 & M, VHE & VHR, VHE, AB \\
\hline AT2 & $\begin{array}{l}21^{\circ} 04^{\prime} 44^{\prime \prime}, \mathrm{S} ; \\
49^{\circ} 32^{\prime} 20^{\prime \prime}, \mathrm{W}\end{array}$ & Temporário & 32 & 0,4 & $\mathrm{~T}, \mathrm{M}, \mathrm{VHE}$ & VHR, VHE, AB \\
\hline $\mathrm{BT}$ & $\begin{array}{l}21^{\circ} 04^{\prime} 24^{\prime \prime}, \mathrm{S} ; \\
49^{\circ} 31^{\prime} 08^{\prime}, \mathrm{W}\end{array}$ & Temporário & 67,5 & 0,4 & VHE, M & VHR, VHE, AB, SN \\
\hline $\mathrm{BP}$ & $\begin{array}{l}21^{\circ} 04^{\prime} 28^{\prime \prime}, \mathrm{S} ; \\
49^{\circ} 31^{\prime} 14^{\prime \prime} \mathrm{W}\end{array}$ & Permanente & 58,5 & 0,27 & VHE & VHE, AB, VHR \\
\hline CA & $\begin{array}{l}21^{\circ} 04^{\prime} 43^{\prime \prime \prime} \mathrm{S} ; \\
49^{\circ} 32^{\prime} 21^{\prime \prime} \mathrm{W}\end{array}$ & Permanente & 1072,5 & 0,5 & - & VHE, T, M \\
\hline $\mathrm{CM}$ & $\begin{array}{l}21^{\circ} 04^{\prime} 28^{\prime \prime}, \mathrm{S} ; \\
49^{\circ} 31^{\prime} 14^{\prime \prime} \mathrm{W}\end{array}$ & Permanente & 211,5 & 0,25 & - & $\mathrm{AB}, \mathrm{VHE}, \mathrm{SN}$ \\
\hline
\end{tabular}

http://www.biotaneotropica.org.br 
Foram amostrados dez corpos d’água, distantes entre si de 20 a $2200 \mathrm{~m}$, com características estruturais (tamanho, duração, velocidade da água) e fisionômicas (vegetação no interior, na margem e ao redor dos corpos d’água) diferentes (Tab. I), selecionados para representar os diferentes tipos de corpos d’água disponíveis para reprodução de anuros na região.

\section{Riqueza e abundância populacional}

As amostragens foram realizadas entre janeiro de 2003 e março de 2004, com freqüência quinzenal na estação chuvosa e mensal na estação seca. A amostragem dos adultos foi realizada durante o turno de vocalização das espécies, entre 19 h e, no máximo, 24 h, e a seqüência de amostragem nos diversos corpos d’água não foi sempre a mesma. A procura dos espécimes foi efetuada pelo método de levantamento por encontro visual (sensu Crump \& Scott 1994). A cada visita, todo o perímetro de cada açude e brejo e os trechos com $50 \mathrm{~m}$ de comprimento selecionados ao longo das margens dos córregos foram percorridos três vezes, contabilizando todos os indivíduos em atividade de vocalização. A abundância de cada espécie foi considerada, segundo Gottsberger \& Gruber (2004), como o número máximo de indivíduos contabilizados em um dos três percursos; a abundância mensal de cada espécie foi considerada, segundo Bertoluci \& Rodrigues (2002), igual à maior abundância quinzenal registrada e a abundância total em cada corpo d’água, ao longo de todo o período estudado, igual à do mês com maior abundância. Essa conduta foi adotada para evitar sub-estimativas de abundância das populações, decorrentes do uso da média de abundância entre amostragens sucessivas, pois o maior número registrado de machos representa de forma mais realista o tamanho da população. Por outro lado, a somatória levaria a uma superestimativa da abundância, como resultado da recontagem de indivíduos em amostragens sucessivas.

Para verificar a eficiência da metodologia de amostragem, foi construída uma curva de rarefação de espécies (Krebs 1999), com 500 aleatorizações, geradas com base na matriz de dados de abundância em cada período de amostragem, num total de 25 amostragens. A riqueza de espécies da área amostrada foi estimada por extrapolação da curva de acumulação de espécies, pelo estimador ICE (Incidence-based Coverage Estimator, Colwell \& Coddington 1994), também com 500 aleatorizações. Ambas as análises foram efetuadas no Programa EstimateS, versão 6.0b1 (Colwell 2000).

A amostragem dos girinos foi iniciada entre 15 e $16 \mathrm{~h}$ e finalizada entre 18 e $19 \mathrm{~h}$. Os girinos foram coletados com puçá de tela de arame com malha de $3 \mathrm{~mm}^{2}$ e cabo longo, passado intensivamente por todo o corpo d'água, desde as margens até a parte central. Os girinos foram anestesiados em solução de benzocaína logo após a coleta, e conservados em formalina a 5\%. Para a identificação, foi utilizada uma chave dicotômica (D. de C. Rossa-Feres \& F. Nomura, dados não publicados).

Os girinos coletados foram depositados na Coleção Científica de Anfíbios do Departamento de Zoologia e Botânica da UNESP, São José do Rio Preto, SP (lotes DZSJRP 136 a 347). Espécimes testemunho dos adultos foram depositados na mesma coleção (Apêndice 1).

Os dados de pluviosidade e temperatura foram obtidos junto à Coordenadoria de Assistência Técnica Integral (CATI) de São José do Rio Preto, São Paulo, cujo posto metereológico está localizado a aproximadamente $8 \mathrm{~km}$ das localidades estudadas.

\section{Análises Estatísticas}

A diversidade de espécies em cada corpo d’água foi determinada pela aplicação do índice de diversidade de Shannon-Wiener (Krebs 1999, Morin 1999), separadamente para girinos e adultos.

O uso de hábitat (corpo d'água) foi analisado com base na composição e na abundância das espécies nas fases adulta e larvária. A diferença na composição de espécies entre os corpos d'água (diversidade $\beta$ ) foi determinada pela aplicação do coeficiente de similaridade de Jaccard (Magurran 1988, Krebs 1999). Para verificar se a distância entre os corpos d'água influenciou a composição de espécies, foi aplicado o teste de correlação de Mantel (Sokal \& Rohlf 1995) entre as matrizes de distância e de similaridade (coeficiente de Jaccard) na composição de espécies. Já a abundância das populações nos diversos corpos de água foi comparada, separadamente para adultos e girinos, pela aplicação do índice de similaridade de Morisita-Horn, com posterior análise de agrupamento pelo método de média não ponderada (UPGMA) (Krebs 1999).

Para verificar a influência da heterogeneidade ambiental dos corpos d'água na ocorrência das espécies, foram determinados seis descritores, categorizados da seguinte maneira:

1. Perfil de margens: 1 = somente margem plana, $2=$ margem plana e em barranco;

2. Tipos de plantas na margem: $1=$ somente com plantas herbáceas rasteiras, 2 = plantas herbáceas rasteiras e eretas, 3 = plantas herbáceas rasteiras, eretas e arbustivo/arbóreas;

3. Porcentagem de cobertura vegetal na superfície da água: 1 = 0-30\%, 2 = 31-60\%, 3 = 61-100\%;

4. Número de tipos de margem: 1 = solo seco sem vegetação, 2 = solo seco com e sem vegetação, 3 = os dois anteriores mais solo úmido sem vegetação, $4=$ os três anteriores mais solo úmido com e sem vegetação, $5=$ os quatro anteriores mais solo alagado sem vegetação, $6=$ os cinco anteriores mais solo alagado com e sem vegetação. 


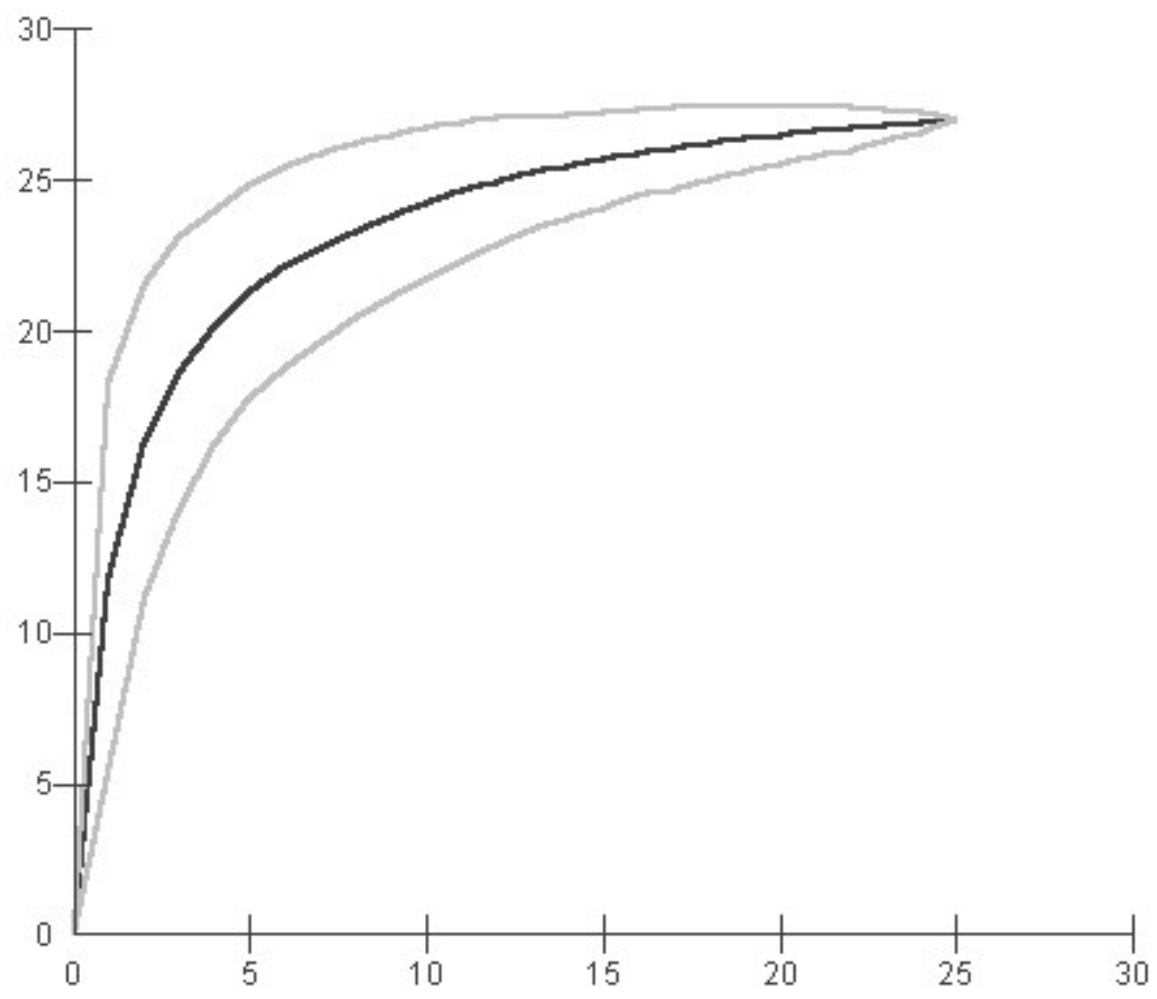

Figura 1: Curva de rarefação de espécies para 25 períodos de amostragem de anuros em Nova Itapirema, São Paulo, entre janeiro de 2003 e março de 2004. A linha preta corresponde à média de cada período de coleta, aleatorizado 500 vezes e as linhas cinzas acima e abaixo correspondem ao desvio-padrão associado.

5. Duração dos corpos d'água: 1 = ambiente permanente, 2 = ambiente temporário de longa duração (superior a cinco meses), 3 = ambiente temporário de curta duração (inferior a cinco meses);

6. Tamanho do corpo d'água: $1=$ pequeno $\left(\leq 100 \mathrm{~m}^{2}\right)$, 2 = médio $\left(100 \mathrm{~m}^{2}<\mathrm{x}<600 \mathrm{~m}^{2}\right), 3$ = grande $\left(\geq 600 \mathrm{~m}^{2}\right)$.

A existência de relação entre o tamanho e a heterogeneidade dos corpos d'água foi verificada pelo teste de correlação de matrizes de Mantel (Sokal \& Rohlf, 1995). Como nenhum dos cinco descritores foi correlacionado com o tamanho do corpo d'água ( $\mathrm{P}>0,05)$, o mesmo teste foi aplicado entre as matrizes de similaridade na composição de espécies (coeficiente de Jaccard) e as matrizes de dissimilaridade de Distância Euclidiana (Krebs 1999) dos seis descritores de cada um dos dez corpos d'água estudados.

Para verificar a influência do volume de chuva e da temperatura sobre a ocorrência e abundância das espécies, o coeficiente de correlação de Spearman ( $\mathrm{r}$; Triola 1999) foi aplicado aos dados de riqueza, abundância, temperatura no dia e pluviosidade acumulada no período de cinco dias antecedentes à data da coleta, utilizando o software BioEstat 3.0 (Ayres et al. 2003). As correlações foram consideradas significativas quando $\mathrm{P} \leq 0,05$, e marginalmente significativa quando $0,05 £ \mathrm{P} \leq 0,10$.

A similaridade temporal na abundância mensal de adultos e girinos ao longo da estação chuvosa foi determinada pela aplicação do índice de similaridade de Morisita-Horn, com análise de agrupamento pelo método de média não ponderada (UPGMA) (Krebs 1999).

A representatividade das matrizes de similaridade nos dendrogramas foi verificada pela determinação do coeficiente de correlação cofenético (r), sendo considerados adequados os dendrogramas com valores de $r \geq 0,8$. Os agrupamentos foram definidos considerando o valor mínimo de $60 \%$ de similaridade. As análises de similaridade foram efetuadas no programa NTSYSpc21 (Rohlf 1989).

\section{RESULTADOS}

\section{Diversidade e uso de hábitat}

Foram registradas 27 espécies pertencentes a nove gêneros de quatro famílias de anuros (Tab. II). Dessas, girinos de 20 espécies foram encontrados (Tab. III). As famílias Leptodactylidae e Hylidae apresentaram a maior riqueza com 12 espécies cada. As famílias com menor número de representantes na região foram Microhylidae (duas espécies) e Bufonidae (uma espécie). A curva de rarefação (Fig. 1) apresentou forte tendência a estabilização na $25^{a}$ amostra (quando o desvio padrão foi zero) em um total de 25 amostras, indicando que, teoricamente, todas as espécies possíveis por este método foram registradas. Reforçando 
essa avaliação, a riqueza de anuros na área estudada, estimada pelo índice de extrapolação de espécies ICE, foi 28,07 espécies $( \pm 0,01)$, uma a mais do que a registrada.

O número de corpos d’água utilizados por uma única espécie variou de um a dez. Cerca de 18,5\% das espécies, considerando adultos e girinos, ocorreram em apenas um (Leptodactylus chaquensis, L. furnarius, L. mystacinus, $L$. cf. ocellatus e Scinax berthae), enquanto que $74,1 \%$ (20 espécies) ocorreram em pelo menos cinco corpos d’água (Fig. 2). As duas espécies restantes (Phrynohyas venulosa e Pseudopaludicola aff. saltica) ocorreram entre dois e quatro corpos d’água (Fig. 2).

A diversidade de espécies não foi correspondente a riqueza, pois alguns corpos d'água com grande riqueza (p. ex. AT1) apresentaram menor diversidade que outros com menor número de espécies (p. ex. AP3 e AP4), em conseqüência da maior uniformidade na abundância das espécies (Fig. 2). Além disso, a riqueza de espécies não foi correlacionada com nenhum dos descritores da heterogeneidade dos corpos d’água (Tab. IV). A riqueza e diversidade da fase larvária foram menores que a dos adultos em todos os corpos d'água e, com exceção do AT1, não corresponderam a da fase adulta (Fig. 2).

A diferença na composição de espécies (diversidade $\beta$ ) entre os corpos d'água estudados foi relativamente baixa e independente da distância entre eles $(r=0,048, P<0,05)$, sendo que apenas as combinações que incluíram os corpos d'água lóticos ou associados à fragmentos de mata ciliar (CA, CM e BP) apresentaram valores de similaridade inferiores a 50\% (Tab. V).

A análise da abundância das populações nos dez corpos d’água evidenciou, para a fase adulta, quatro agrupamentos (Fig. 3, Tab. II): (1) temporários (AT1 e AT2) que apresentaram diversidade intermediária, com grande riqueza mas dominância de $P$. nattereri e (2) permanentes (AP1 e AP2), que apresentaram diversidade intermediária, com menor riqueza de espécies e grande dominância de Hyla nana; (3) permanentes (AP3 e AP4) e temporário (BT), que apresentaram os maiores valores de diversidade de espécies; (4) córregos (CA e CM) e brejo permanente associado à mata ciliar (BP), que apresentaram os menores valores de diversidade de espécies. Já com base na abundância dos girinos (Tab. III) os corpos d'água foram agrupados em (Fig. 4): (1) temporários (AT1, AT2 e BT), que apresentaram elevada diversidade de girinos; (2) permanentes (AP1, AP3 e AP4) que, apesar dos diferentes valores de diversidade, apresentaram composição de espécies semelhante e; (3) córregos (CA, $\mathrm{CM})$ e brejo associado à mata ciliar (BP), que apresentaram os menores valores de diversidade de girinos.

\section{Ocorrência temporal}

Na região estudada, a riqueza de espécies foi correlacionada com os índices pluviométricos $\left(\mathrm{r}_{\text {Sadultos }}\right.$ $\left.=0,82, \mathrm{P}=0,00 ; \mathrm{r}_{\text {Sgirinos }}=0,85, \mathrm{P}=0,00\right)$ e com a temperatura média mensal ( $\mathrm{r}_{\text {Sadultos }}=0,65, \mathrm{P}=0,01 ; \mathrm{r}_{\text {Sgirinos }}$ $=0,67, \mathrm{P}=0,01)$, sendo que a maior riqueza de machos em atividade de vocalização ocorreu em outubro de 2003 (25 espécies, Fig. 5), coincidindo com o início da estação chuvosa na região. No entanto, apenas em dois corpos d’água a maior riqueza de machos em atividade de vocalização ocorreu no mês de outubro: AT1 (16 espécies) e AP1 (10 espécies) (Tab. VI). Nos demais corpos d'água o pico de riqueza ocorreu em novembro ou dezembro (Tab. VI). A maior riqueza de girinos foi registrada entre outubro de 2004 (AT1) e fevereiro de 2005 (BP) (Tab. VI). De modo geral, a riqueza mensal de adultos e girinos foi correlacionada com a precipitação pluviométrica e com a temperatura média mensais nos dez corpos d’água estudados, com exceção apenas para riqueza de girinos em três corpos d’água (AP1, AP4, CA) e de adultos no AP1 (Tab. VI). A abundância mensal das populações de adultos e de girinos também foi correlacionada com os índices pluviométricos $\left(\mathrm{r}_{\text {Sadultos }}=0,82 ; \mathrm{P}=0,00 ; \mathrm{r}_{\text {Sgirinos }}=0,67\right.$; $\mathrm{P}=0,01)$ e com a temperatura $\left(\mathrm{r}_{\text {Sadultos }}=0,62, \mathrm{P}=0,01\right.$; $\left.r_{\text {Sgirinos }}=0,53, P=0,04\right)$.

A análise da variação temporal na abundância mensal de machos em atividade de vocalização evidenciou três agrupamentos de espécies (Fig. 6): (1) espécies que apresentaram as maiores abundâncias somente nos primeiros meses da estação chuvosa (setembro e outubro) - Bufo schneideri, Leptodactylus chaquensis, L. cf. ocellatus, L. mystacinus, Physalaemus fuscomaculatus, P. nattereri, Phrynohyas venulosa e Scinax berthae; (2) espécies que ocorreram ao longo da estação chuvosa, mas com maior abundância em plena estação (novembro a janeiro) Elachistocleis bicolor, Elachistocleis sp., Hyla elianeae, $H$. minuta, $H$. nana, $H$. raniceps, $L$. fuscus, $L$. labyrinthicus, $L$. podicipinus, P. centralis, P. cuvieri, Pseudis paradoxa, Pseudopaludicola aff. saltica, S. fuscovarius e S. aff. similis; (3) espécies que vocalizaram durante toda a estação chuvosa, mas com maior abundância no final da estação (fevereiro e março) - H. albopunctata, H. sanborni e S. fuscomarginatus.

Com base na abundância mensal de girinos, as espécies podem, novamente, ser separadas em três agrupamentos (Fig. 7). A composição desses agrupamentos, principalmente a do agrupamento 3 , difere da dos adultos, mas o padrão de ocorrência temporal que caracteriza cada agrupamento é semelhante: (1) girinos encontrados somente no início da estação chuvosa (principalmente em outubro e novembro) Bufo schneideri, L. labyrinthicus, L. cf. ocellatus, Physalaemus nattereri e Phrynohyas venulosa; (2) girinos encontrados ao longo da estação chuvosa, mas com maior abundância nos últimos meses desta estação (fevereiro e março) - Elachistocleis sp., $H$. albopunctata, $H$. minuta, $H$. nana e $P$. centralis; (3) girinos encontrados somente ou com maior abundância em plena estação chuvosa (dezembro e 


\begin{tabular}{|c|c|c|c|c|c|c|c|c|c|c|}
\hline & AP1 & AP2 & AP3 & AP4 & AT1 & AT2 & BT & BP & $\mathrm{CA}$ & CM \\
\hline Bp & "21IIIII & & IIIIII & IIIII & IIIIII & & & & & \\
\hline $\mathrm{Eb}$ & & 7IIIII: & & & IIIIII: & & IIIIIII & & & \\
\hline Esp & & $m m$ & mया & mim & mIII & & IIIII & mIIII: & & \\
\hline $\mathrm{Ha}$ & आIIII & & IIIII: & IIIIIII & & & mIIII & IIIII & ZZZ & IIIII) \\
\hline $\mathrm{He}$ & & & & & & & & & & \\
\hline $\mathrm{Hm}$ & & & IIIII & IIIIII & & & IIIIII & IIIII & & -1 \\
\hline $\mathrm{Hn}$ & 'IIIIIII & TIIIII & IIIIII & & पIIIII: & IIIII & mIII: & & & \\
\hline $\mathrm{Hr}$ & "11101 & MIII & mIIII & & IIIII: & mIII: & & & & \\
\hline $\mathrm{Hs}$ & $\square$ &  & & & 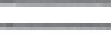 & & $=$ & & & \\
\hline Lch & & & & & 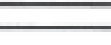 & & & & & \\
\hline Lf &  & & & & & & & & & \\
\hline Lfr & & & & & & & & & ב & \\
\hline Ll & & & & & & & & & & IIIIII \\
\hline Lmy & & & & 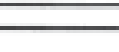 & & & & & & \\
\hline Lo & & & & & IIIIII & & & & & \\
\hline Lp & IIII & III & IIII & & $M M I I I$ & IIIII & mIm & & & \\
\hline $\mathrm{P} \propto$ & & 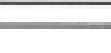 & & & & & & & & \\
\hline Pcu & & III)!n & & & & & & & & \\
\hline Pfm & & MII & & וחוחו & TIII &  & & & & mII \\
\hline Ps & & IIIIII & IIIIIII & & & & & IIIIII & & \\
\hline Pn & $\mathbb{Z}$ & MIII & & & IIIII) & & & & & \\
\hline Pp & & IIIII & & & IIIIIII & IIIII & & & & \\
\hline Pv & & & & & mIIII & 二 & & & & \\
\hline $\mathrm{Sb}$ & $\square$ & & & & & & & & & \\
\hline Sfm & יודיודי & IIIII & r:Pr: & יח & דודידוד & $m$ & IIIII & & & \\
\hline Sfv & & $\mathbb{Z I I}$ & & & & & & & & \\
\hline Ss & & & & & mIIII & पाm & $\mathbb{T}$ & mIII & & \\
\hline $\begin{array}{c}\text { Riqueza } \\
\text { total }\end{array}$ & 15 & 17 & 18 & 20 & 20 & 19 & 18 & 13 & 11 & 10 \\
\hline Riqueza & & & & & & & & & & \\
\hline adultos & 15 & 16 & 17 & 18 & 20 & 18 & 18 & 8 & 10 & 7 \\
\hline H'ad & 0,868 & 0,807 & 1,007 & 1,006 & 0,868 & 0,95 & 1,106 & 0,81 & 0,809 & 0,596 \\
\hline e ad & 0,738 & 0,67 & 0,818 & 0,787 & 0,667 & 0,757 & 0,881 & 0,896 & 0,809 & 0,705 \\
\hline Riqueza & & & & & & & & & & \\
\hline $\begin{array}{l}\text { girinos } \\
\text { H'gir }\end{array}$ & $\begin{array}{c}10 \\
0.366\end{array}$ & $\begin{array}{c}14 \\
0.665\end{array}$ & $\begin{array}{c}14 \\
0.675\end{array}$ & $\begin{array}{c}11 \\
0.394\end{array}$ & $\begin{array}{c}16 \\
0.563\end{array}$ & $\begin{array}{c}12 \\
0.409\end{array}$ & $\begin{array}{c}13 \\
0.556\end{array}$ & $\begin{array}{c}11 \\
0.493\end{array}$ & $\begin{array}{c}3 \\
0.032\end{array}$ & $\stackrel{6}{6}$ \\
\hline egir & 0,391 & 0,541 & 0,589 & 0,368 & 0,465 & 0,367 & $\begin{array}{l}0,490 \\
0,492\end{array}$ & $\begin{array}{c}0,493 \\
0,48\end{array}$ & $\begin{array}{l}0,032 \\
0,067\end{array}$ & 0,38 \\
\hline
\end{tabular}

Figura 2: Ocorrência de adultos (barras brancas) e girinos (barras hachuradas) das 27 espécies de anuros registradas nos dez corpos d'água estudados em Nova Itapirema, São Paulo. Bs = Bufo schneideri, $E b=$ Elachistocleis bicolor, Esp = Elachistocleis sp., Ha = Hyla albopunctata, $H e=\mathrm{H}$. elianeae, $\mathrm{Hm}=\mathrm{H}$. minuta, $\mathrm{Hn}=\mathrm{H}$. nana, $H r=\mathrm{H}$. raniceps, $H s=\mathrm{H}$. sanborni, $L c h=$ Leptodactylus chaquensis, $L f r=\mathrm{L}$. furnarius, $L f$ $=$ L. fuscus, $L l=\mathrm{L}$. labyrinthicus, $L m y=\mathrm{L}$. mystacinus, $L o=\mathrm{L}$. $c f$. ocellatus, $L p=$ L. podicipinus, $P c e=$ Physalaemus centralis, $P c u=\mathrm{P}$. cuvieri, $P f m=$ P. fuscomaculatus, $P n=$ Physalaemus nattereri, $P p=$ Pseudis paradoxa, $P s=$ Pseudopaludicola aff. saltica, $P v=$ Phrynohyas venulosa, $S b=$ Scinax berthae, $S f m=$ S. fuscomarginatus, $S f v=$ S. fuscovarius, $S s=$ S. aff. similis. Riqueza total = riqueza de espécies considerando adultos e girinos. Riqueza adultos e Riqueza girinos = riqueza de espécies com base na amostragem de adultos e girinos, respectivamente. "H'ad" e "H'gir" = índice de diversidade de Shannon-Wiener e "e ad" e "e gir" = índice de uniformidade de Pielou com base na amostragem de adultos e de girinos, respectivamente. Abreviações e características dos corpos d'água na Tabela I. 


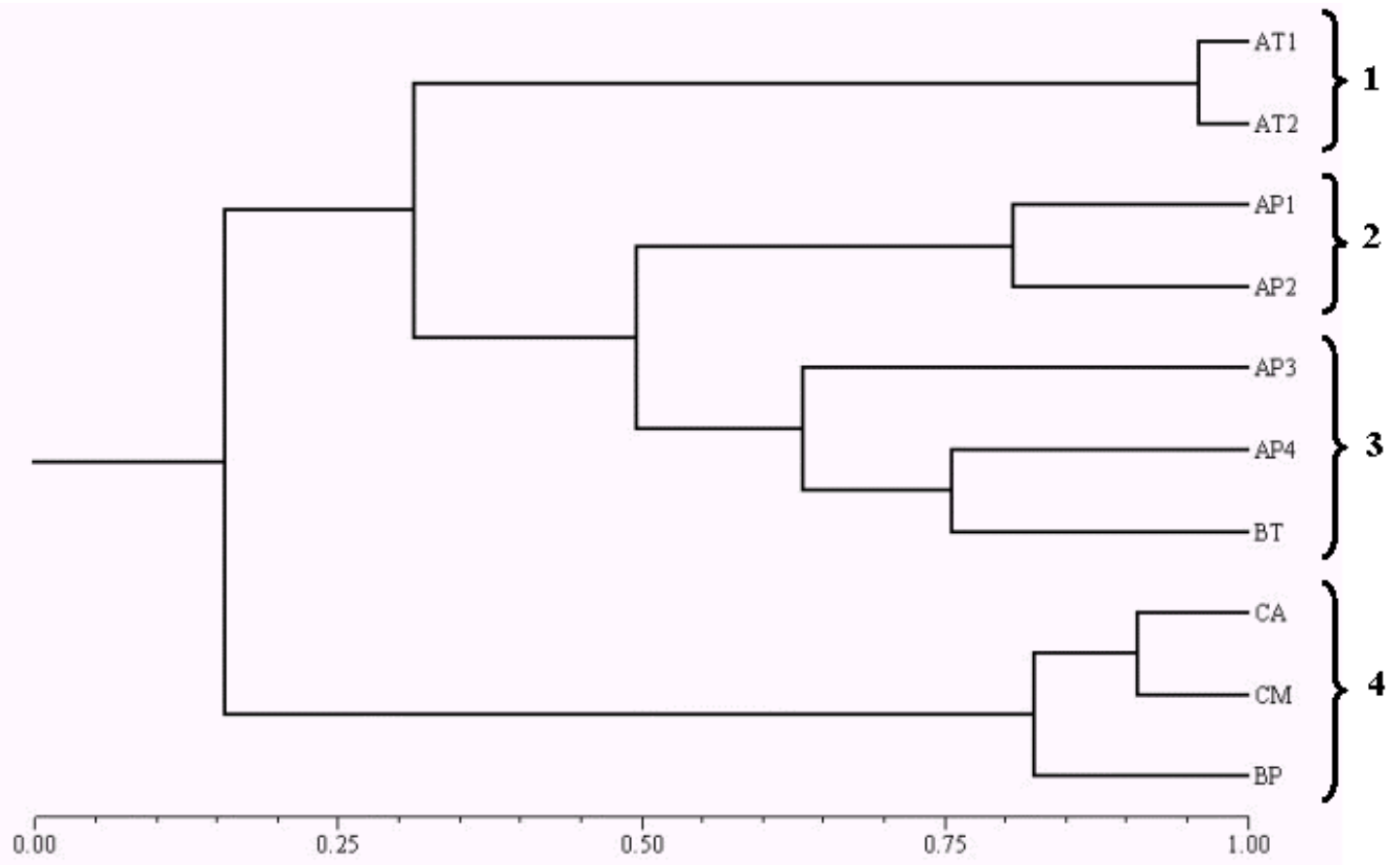

Figura 3: Similaridade entre os dez corpos d'água estudados em Nova Itapirema, São Paulo, com base na abundância de adultos em atividade de vocalização. Os números indicam os agrupamentos com similaridade superior a 60\%. Coeficiente de correlação cofenético = 0,92. Abreviações e características dos corpos d’água na Tabela I.



Figura 4: Similaridade entre os dez corpos d'água estudados em Nova Itapirema, São Paulo, com base na abundância de girinos. Os números indicam os agrupamentos com similaridade superior a $60 \%$. Coeficiente de correlação cofenético = 0,9. Abreviações e características dos corpos d'água na Tabela I.

http://www.biotaneotropica.org.br 


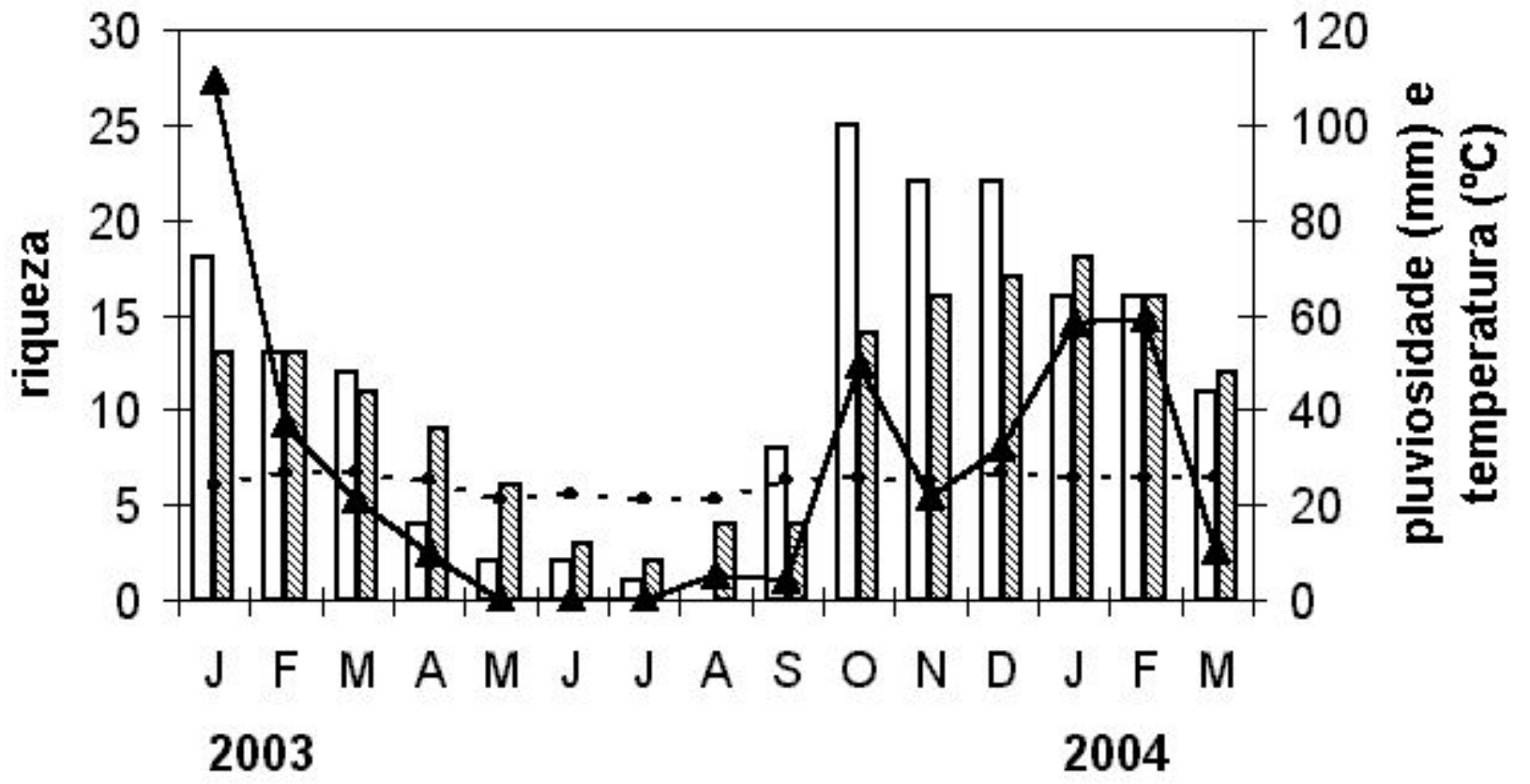

Figura 5: Distribuição temporal da riqueza de anuros adultos (barras brancas) e de girinos (barras hachuradas), pluviosidade média acumulada dos cinco dias anteriores à coleta (linha) e temperatura (linha pontilhada), no conjunto dos dez corpos d'água estudados em Nova Itapirema, São Paulo, no período de janeiro de 2003 a março de 2004 (J a M).

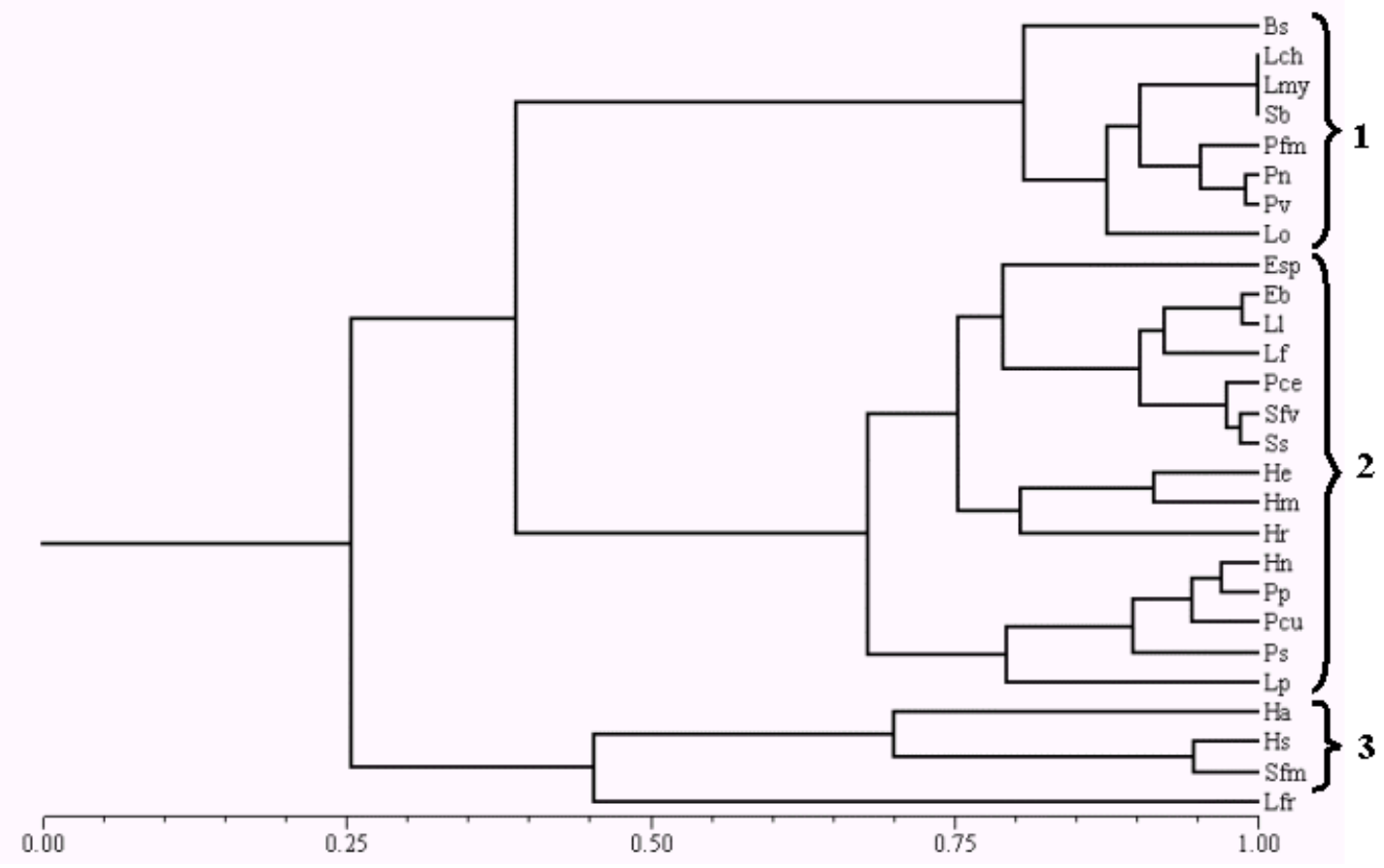

Figura 6: Similaridade na ocorrência temporal de machos em atividade de vocalização, no período de setembro de 2003 a março de 2004, no conjunto dos dez ambientes estudados em Nova Itapirema, São Paulo. Os números indicam os agrupamentos com similaridade superior $a 60 \%$. Bs = Bufo schneideri, $E b=$ Elachistocleis bicolor, $E s p=$ Elachistocleis sp., $H a=$ Hyla albopunctata, $H e=H$. elianeae, $H m=H$. minuta, $H n=$ H. nana, $H r=$ H. raniceps, $H s=H$. sanborni, $L c h=$ Leptodactylus chaquensis, $L f=$ L. fuscus, $L f r=L$. furnarius, $L l=L$. labyrinthicus, $L m y$ $=$ L. mystacinus, $L o=$ L. $c f$. ocellatus, $L p=$ L. podicipinus, $P c e=$ Physalaemus centralis, $P c u=P$. cuvieri, $P f m=$ P. fuscomaculatus, $P n=$ Physalaemus nattereri, $P p=$ Pseudis paradoxa, $P s=$ Pseudopaludicola $a f f$. saltica, $P v=$ Phrynohyas venulosa, $S b=\mathrm{Scinax}$ berthae, $S f m=\mathrm{S}$. fuscomarginatus, $S f v=\mathrm{S}$. fuscovarius, $S s=\mathrm{S}$. aff. similis. Coeficiente de correlação cofenético =0,8. 


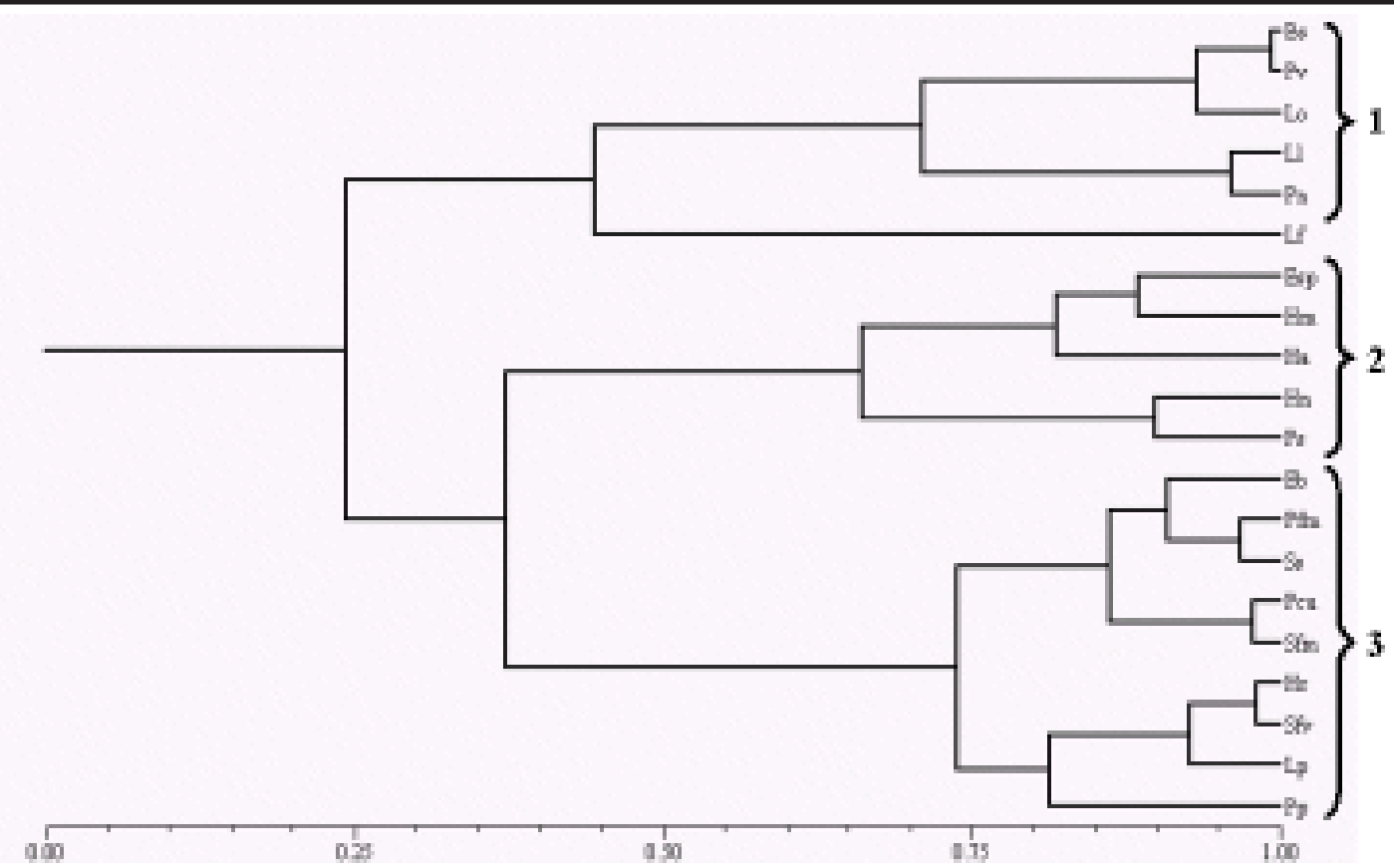

Figura 7: Similaridade na ocorrência temporal de girinos de anuros no período de setembro de 2003 a março de 2004 , no conjunto dos dez corpos d'água estudados em Nova Itapirema, São Paulo. Os números indicam os agrupamentos com similaridade superior a 60\%. Bs = Bufo schneideri, $E b=$ Elachistocleis bicolor, $E s p=$ Elachistocleis sp., $\mathrm{Ha}=$ Hyla albopunctata, $\mathrm{Hm}=\mathrm{H}$. minuta, $\mathrm{Hn}=\mathrm{H}$. nana, $\mathrm{Hr}=\mathrm{H}$. raniceps, $L f=$ L. fuscus, $L l=$ L. labyrinthicus, $L o=$ L. $c f$. ocellatus, $L p=$ L. podicipinus, $P c u=$ P. cuvieri, $P f m=$ P. fuscomaculatus, $P n=$ Physalaemus nattereri, $P p=$ Pseudis paradoxa, $P s=$ Pseudopaludicola $a f f$. saltica, $P v=$ Phrynohyas venulosa, $S f m=S$. fuscomarginatus, $S f v=S$. fuscovarius, Ss $=$ S. aff. similis. Coeficiente de correlação cofenético $=0,85$.

Tabela II: Abundância das 27 espécies registradas em Nova Itapirema, São Paulo, em cada um e no conjunto dos 10 corpos d’água estudados (Total).

\begin{tabular}{lccccccccccc}
\hline Espécies & AP1 & AP2 & AP3 & AP4 & AT1 & AT2 & BT & BP & CA & CM & TOTAL \\
\hline Bufo schneideri & 4 & 4 & 0 & 5 & 1 & 0 & 0 & 0 & 0 & 0 & 14 \\
Elachistocleis bicolor & 0 & 5 & 1 & 7 & 25 & 10 & 7 & 0 & 0 & 0 & 55 \\
Elachistocleis sp. & 2 & 7 & 1 & 8 & 5 & 1 & 20 & 2 & 2 & 2 & 50 \\
Hyla albopunctata & 4 & 0 & 2 & 1 & 0 & 0 & 4 & 8 & 12 & 14 & 45 \\
H. elianeae & 0 & 0 & 3 & 70 & 9 & 1 & 20 & 0 & 0 & 0 & 103 \\
H. minuta & 0 & 0 & 13 & 50 & 0 & 2 & 15 & 3 & 0 & 1 & 84 \\
H. nana & 40 & 150 & 25 & 30 & 30 & 15 & 30 & 1 & 1 & 1 & 323 \\
H. raniceps & 2 & 4 & 1 & 3 & 4 & 1 & 1 & 0 & 0 & 0 & 16 \\
H. sanborni & 20 & 100 & 0 & 0 & 20 & 3 & 3 & 0 & 0 & 0 & 146 \\
Leptodactylus chaquensis & 0 & 0 & 0 & 0 & 2 & 0 & 0 & 0 & 0 & 0 & 2 \\
L. fuscus & 2 & 10 & 4 & 8 & 20 & 4 & 10 & 0 & 2 & 0 & 60 \\
L. furnarius & 0 & 0 & 0 & 0 & 0 & 0 & 0 & 0 & 4 & 0 & 4 \\
L. labyrinthicus & 0 & 0 & 1 & 1 & 0 & 0 & 0 & 0 & 0 & 1 & 3 \\
L. mystacinus & 0 & 0 & 0 & 1 & 0 & 0 & 0 & 0 & 0 & 0 & 1 \\
L. cf. ocellatus & 0 & 0 & 0 & 0 & 2 & 0 & 0 & 0 & 0 & 0 & 2 \\
L. podicipinus & 45 & 35 & 3 & 10 & 23 & 13 & 18 & 0 & 1 & 1 & 149 \\
Physalaemus centralis & 0 & 6 & 0 & 5 & 30 & 5 & 2 & 1 & 1 & 0 & 50 \\
P. cuvieri & 2 & 6 & 7 & 4 & 4 & 1 & 15 & 6 & 5 & 7 & 57 \\
P. fuscomaculatus & 0 & 0 & 0 & 3 & 12 & 8 & 3 & 0 & 0 & 0 & 26 \\
P. nattereri & 8 & 10 & 1 & 30 & 250 & 70 & 10 & 0 & 1 & 0 & 380 \\
Phrynohyas venulosa & 0 & 0 & 0 & 0 & 10 & 3 & 0 & 0 & 0 & 0 & 13 \\
Pseudis paradoxa & 1 & 5 & 1 & 1 & 6 & 7 & 1 & 0 & 0 & 0 & 22 \\
Pseudopaludicola aff. saltica & 1 & 10 & 15 & 0 & 0 & 0 & 0 & 3 & 0 & 0 & 29 \\
Scinax berthae & 8 & 0 & 0 & 0 & 0 & 0 & 0 & 0 & 0 & 0 & 8 \\
S. fuscomarginatus & 10 & 18 & 5 & 27 & 35 & 8 & 10 & 0 & 0 & 0 & 113 \\
S. fuscovarius & 0 & 1 & 6 & 15 & 7 & 9 & 4 & 0 & 1 & 0 & 43 \\
S. aff. similis & 1 & 4 & 4 & 0 & 5 & 11 & 2 & 3 & 0 & 0 & 30 \\
\hline
\end{tabular}

http://www.biotaneotropica.org.br 
Tabela III: Abundância dos girinos de 20 das 27 espécies registradas em Nova Itapirema, São Paulo, em cada um e no conjunto dos 10 corpos d'água estudados (Total).

\begin{tabular}{lccccccccccc}
\hline & AP1 & AP2 & AP3 & AP4 & AT1 & AT2 & BT & BP & CA & CM & TOTAL \\
\hline Bufo schneideri & 1378 & 0 & 1219 & 11752 & 14 & 0 & 0 & 0 & 0 & 0 & 14363 \\
Elachistocleis bicolor & 0 & 4 & 0 & 0 & 3 & 0 & 3 & 0 & 0 & 0 & 10 \\
Elachistocleis sp. & 0 & 10 & 1 & 1 & 4 & 0 & 97 & 11 & 0 & 0 & 124 \\
Hyla albopunctata & 31 & 0 & 447 & 5 & 0 & 1 & 132 & 399 & 616 & 1421 & 3052 \\
H. minuta & 0 & 0 & 67 & 381 & 0 & 0 & 22 & 3 & 0 & 0 & 473 \\
H. nana & 29 & 388 & 37 & 0 & 323 & 76 & 8 & 0 & 0 & 0 & 877 \\
H. raniceps & 9 & 44 & 1 & 0 & 7 & 45 & 0 & 0 & 0 & 0 & 106 \\
Leptodactylus fuscus & 0 & 2 & 25 & 51 & 51 & 6 & 27 & 6 & 0 & 1 & 169 \\
L. labyrinthicus & 0 & 0 & 0 & 0 & 0 & 0 & 0 & 4 & 1 & 44 & 49 \\
L. cf. ocellatus & 0 & 0 & 0 & 0 & 188 & 0 & 0 & 0 & 0 & 0 & 188 \\
L. podicipinus & 483 & 1021 & 1 & 0 & 55 & 182 & 157 & 0 & 0 & 0 & 1899 \\
P. cuvieri & 17 & 458 & 570 & 38 & 567 & 73 & 716 & 481 & 7 & 468 & 3395 \\
P. fuscomaculatus & 0 & 1 & 0 & 5 & 51 & 10 & 45 & 7 & 0 & 5 & 124 \\
P. nattereri & 8 & 47 & 1 & 464 & 3213 & 3254 & 2391 & 1 & 0 & 1 & 9380 \\
Phrynohyas venulosa & 0 & 0 & 0 & 0 & 5 & 0 & 0 & 0 & 0 & 0 & 5 \\
Pseudis paradoxa & 0 & 54 & 0 & 0 & 15 & 4 & 0 & 0 & 0 & 0 & 73 \\
Pseudopaludicola aff. saltica & 0 & 9 & 19 & 0 & 0 & 0 & 0 & 33 & 0 & 0 & 61 \\
Scinax fuscomarginatus & 1 & 48 & 25 & 2 & 7 & 1 & 22 & 0 & 0 & 0 & 106 \\
S. fuscovarius & 0 & 4 & 298 & 9341 & 439 & 963 & 4019 & 32 & 0 & 0 & 15096 \\
S. aff. similis & 11 & 81 & 30 & 113 & 39 & 27 & 108 & 5 & 0 & 0 & 414 \\
\hline
\end{tabular}

Tabela IV: Correlação entre a riqueza de espécies e os descritores ambientais dos corpos d'água estudados em Nova Itapirema, São Paulo, pelo teste de correlação de matrizes de Mantel. $r=$ valor da estatística do teste; $p=$ nível de significância do teste.

\begin{tabular}{lcc}
\hline Descritores ambientais & $\mathrm{r}$ & $\mathrm{p}$ \\
\hline Perfil de margens & $-0,37$ & 0,20 \\
Tipos de plantas na margem & 0,13 & 0,40 \\
Porcentagem de cobertura vegetal na água & $-0,14$ & 0,13 \\
Número de tipos de margem & 0,05 & 0,29 \\
Duração dos corpos d'água & 0,16 & 0,31 \\
Tamanho dos corpos d'água & 0,11 & 0,25 \\
\hline
\end{tabular}

Tabela V: Similaridade entre os dez corpos d'água estudados em Nova Itapirema, São Paulo, com base na composição de espécies de anuros. Valores inferiores a 50\% (negrito) indicam as combinações onde a diversidade $\beta$ foi considerada alta. Em itálico, o número de espécies comum entre os corpos d'água.

\begin{tabular}{ccccccccccc}
\hline & AP1 & AP2 & AP3 & AP4 & AT1 & AT2 & BT & BP & CA & CM \\
\hline AP1 & $*$ & 68,42 & 61,90 & 52,17 & 52,17 & 54,55 & 57,14 & $\mathbf{4 0}$ & $\mathbf{3 6 , 8 4}$ & $\mathbf{3 8 , 8 9}$ \\
AP2 & 13 & $*$ & 71,43 & 68,18 & 76,19 & 71,43 & 75 & 50 & $\mathbf{4 0}$ & $\mathbf{3 5}$ \\
AP3 & 13 & 15 & $*$ & 85,71 & 62,50 & 72,73 & 76,19 & 60 & 50 & $\mathbf{4 5}$ \\
AP4 & 12 & 15 & 18 & $*$ & 66,67 & 77,27 & 80,95 & 57,14 & $\mathbf{4 7 , 6 2}$ & 50 \\
AT1 & 12 & 16 & 15 & 16 & $*$ & 77,27 & 72,73 & $\mathbf{3 7 , 5 0}$ & $\mathbf{3 4 , 7 8}$ & $\mathbf{3 0 , 4 3}$ \\
AT2 & 12 & 15 & 16 & 17 & 17 & $*$ & 94,74 & 52,38 & $\mathbf{4 2 , 8 6}$ & $\mathbf{4 5}$ \\
BT & 12 & 15 & 16 & 17 & 16 & 18 & $*$ & 55 & $\mathbf{4 5}$ & $\mathbf{4 7 , 3 7}$ \\
BP & 8 & 11 & 12 & 12 & 9 & 11 & 11 & $*$ & 60 & 64,29 \\
CA & 7 & 8 & 10 & 10 & 8 & 9 & 9 & 9 & $*$ & 61,54 \\
CM & 7 & 7 & 9 & 10 & 7 & 9 & 9 & 9 & 8 & $*$
\end{tabular}


Tabela VI: Riqueza mensal de adultos e girinos no conjunto dos dez corpos d'água estudados em Nova Itapirema, São Paulo, entre janeiro de 2003 e março de 2004 ( $J-M)$; p = nível de significância da correlação entre o volume de chuva acumulado no período de cinco dias antecedentes à data da coleta $[\mathrm{p}(\mathrm{mm})]$ e a temperatura $\left[p\left({ }^{\circ} \mathrm{C}\right)\right]$ com a riqueza de espécies.

\begin{tabular}{llccccccccccccccccc}
\hline & & $\mathrm{J}$ & $\mathrm{F}$ & $\mathrm{M}$ & $\mathrm{A}$ & $\mathrm{M}$ & $\mathrm{J}$ & $\mathrm{J}$ & $\mathrm{A}$ & $\mathrm{S}$ & $\mathrm{O}$ & $\mathrm{N}$ & $\mathrm{D}$ & $\mathrm{J}$ & $\mathrm{F}$ & $\mathrm{M}$ & $\mathrm{p}(\mathrm{mm})$ & $\mathrm{p}\left({ }^{\circ} \mathrm{C}\right)$ \\
\hline $\mathrm{AP1}$ & Adultos & 5 & 3 & 2 & 1 & 0 & 0 & 0 & 0 & 4 & 10 & 6 & 5 & 2 & 4 & 1 & 0,01 & 0,05 \\
& Girinos & 2 & 2 & 2 & 0 & 0 & 1 & 1 & 1 & 1 & 2 & 7 & 5 & 2 & 1 & 0 & 0,16 & 0,05 \\
$\mathrm{AP2}$ & Adultos & 12 & 8 & 6 & 1 & 0 & 1 & 0 & 0 & 3 & 12 & 14 & 11 & 7 & 7 & 1 & 0,00 & 0,01 \\
& Girinos & 7 & 7 & 3 & 4 & 2 & 1 & 0 & 1 & 0 & 3 & 6 & 12 & 7 & 8 & 4 & 0,00 & 0,00 \\
AP3 & Adultos & 8 & 6 & 4 & 2 & 1 & 0 & 1 & 0 & 2 & 6 & 11 & 11 & 7 & 5 & 5 & 0,00 & 0,00 \\
& Girinos & 6 & 4 & 4 & 3 & 3 & 2 & 2 & 2 & 2 & 6 & 7 & 7 & 10 & 9 & 8 & 0,01 & 0,00 \\
AP4 & Adultos & 10 & 7 & 8 & 2 & 1 & 1 & 1 & 0 & 1 & 5 & 12 & 13 & 9 & 8 & 6 & 0,00 & 0,00 \\
& Girinos & 2 & 3 & 5 & 4 & 3 & 2 & 2 & 2 & 2 & 3 & 7 & 4 & 4 & 5 & 5 & 0,25 & 0,03 \\
AT1 & Adultos & 7 & 5 & 4 & 0 & 0 & 0 & 0 & 0 & 1 & 16 & 13 & 8 & 7 & 5 & 1 & 0,01 & 0,01 \\
& Girinos & 5 & 5 & 2 & 2 & 1 & 0 & 0 & 0 & 0 & 10 & 10 & 10 & 7 & 5 & 1 & 0,01 & 0,02 \\
AT2 & Adultos & 6 & 3 & 0 & 0 & 0 & 0 & 0 & 0 & 0 & 9 & 10 & 8 & 6 & 6 & 2 & 0,01 & 0,03 \\
& Girinos & 5 & 4 & 0 & 0 & 0 & 0 & 0 & 0 & 0 & 2 & 3 & 7 & 10 & 7 & 7 & 0,00 & 0,00 \\
BT & Adultos & 10 & 7 & 6 & 2 & 2 & 1 & 0 & 0 & 1 & 5 & 8 & 12 & 5 & 11 & 6 & 0,00 & 0,00 \\
& Girinos & 11 & 6 & 7 & 4 & 2 & 2 & 2 & 0 & 0 & 2 & 6 & 8 & 7 & 8 & 6 & 0,01 & 0,00 \\
BP & Adultos & 3 & 2 & 2 & 1 & 0 & 0 & 0 & 0 & 1 & 2 & 5 & 5 & 4 & 4 & 2 & 0,00 & 0,00 \\
& Girinos & 2 & 4 & 5 & 3 & 1 & 1 & 1 & 2 & 3 & 4 & 4 & 4 & 3 & 7 & 4 & 0,02 & 0,00 \\
$\mathrm{CA}$ & Adultos & 3 & 3 & 1 & 1 & 1 & 0 & 0 & 0 & 0 & 2 & 8 & 4 & 4 & 1 & 1 & 0,01 & 0,03 \\
& Girinos & 0 & 1 & 1 & 1 & 1 & 1 & 1 & 1 & 1 & 1 & 1 & 3 & 2 & 1 & 1 & 0,88 & 0,96 \\
$\mathrm{CM}$ & Adultos & 2 & 2 & 2 & 1 & 1 & 0 & 0 & 0 & 2 & 3 & 3 & 4 & 2 & 2 & 1 & 0,00 & 0,02 \\
& Girinos & 3 & 2 & 3 & 2 & 1 & 1 & 1 & 1 & 1 & 3 & 3 & 4 & 4 & 4 & 1 & 0,00 & 0,01 \\
\hline
\end{tabular}

janeiro) - Elachistocleis bicolor, H. raniceps, L. podicipinus, P. fuscomaculatus, P. cuvieri, Pseudis paradoxa, S. fuscomarginatus, $S$. fuscovarius, $S$. aff. similis.

\section{DISCUSSÃO}

Hylidae e Leptodactylidae foram as famílias com maior número de espécies na área estudada, repetindo o padrão encontrado na região neotropical (Duellman 1988; Achaval \& Olmos 2003; Straneck et al. 1993), e mais especificamente, em diversos biomas do Brasil, como relatado em Haddad \& Sazima (1992), Brandão \& Araújo (1998), Bernarde \& Machado (2001), Izecksohn \& Carvalhoe-Silva (2001) e Pombal \& Gordo (2004).

Na literatura atual, 28 espécies de anuros estão registradas para a região noroeste do estado de São Paulo (Vizotto 1967, Cais 1992, Rossa-Feres \& Jim 2001, Bernarde \& Kokubum 1999). No presente estudo, quatro espécies (Leptodactylus chaquensis, L. furnarius, L. mystacinus e Scinax berthae) são acrescentadas à listagem regional. Somente Dermatonotus muelleri, registrada por Vizotto (1967), e S. perereca, L. mystaceus e Pseudopaludicola falcipes, registradas em Guararapes por Bernarde \& Kokubum (1999), não foram encontradas nos corpos d'água estudados.

A riqueza de espécies não foi relacionada com os descritores da heterogeneidade dos corpos d’água, e sim com as condições climáticas (temperatura e chuva). A influência do clima na ocorrência e atividade reprodutiva de comunidades de anuros de regiões tropicais é determinada principalmente pela distribuição e volume de chuva
(Duellman \& Trueb 1994). Em regiões tropicais com sazonalidade bem marcada, a ocorrência e a reprodução de grande parte das espécies estão restritas à estação chuvosa (p.ex., Donnelly \& Guyer 1994, Rossa-Feres \& Jim 1994, Bertoluci \& Rodrigues 2002, Prado et al. 2004). Em regiões mais úmidas e sem sazonalidade marcada, como na Mata Atlântica, de $11 \%$ a $16 \%$ das espécies se reproduzem ao longo do ano (Bertoluci \& Rodrigues 2002), enquanto em regiões com estação seca severa, como na Caatinga brasileira, não é conhecido para nenhuma espécie reprodução contínua (Arzabe 1999). A região estudada tem uma pronunciada estação seca que recebe, em média, apenas 15\% da precipitação pluviométrica anual (Barcha \& Arid 1971). Nessa região, 92,6\% das 27 espécies ocorreram apenas na estação chuvosa e somente duas espécies $(7,4 \%)$ ocorreram ao longo do ano. Assim, quanto mais severa a estação seca, maior é o número de espécies com ocorrência restrita à estação chuvosa. Apesar da pequena amplitude de variação térmica na área estudada, houve correlação entre a ocorrência das espécies e a temperatura. Estudos desenvolvidos em regiões com estações bem definidas têm encontrado correlação entre o número de espécies em atividade reprodutiva e a temperatura (p.ex., Toledo et al. 2003, Prado et al. 2004), entretanto, é importante ressaltar que essas variáveis provavelmente são correlacionadas.

Apenas quatro modos reprodutivos foram encontrados (sensu Duellman \& Trueb 1994, Prado et al. 2002, Haddad \& Prado 2005): (1) ovos e girinos depositados diretamente em ambiente lêntico; (2) ovos em ninhos de espuma depositados diretamente em ambiente lêntico; (3) ovos em ninhos de espuma depositados em depressões 
escavadas pelo macho em corpos de corpos d’água lêntico; (4) ovos em ninhos de espuma em câmaras subterrâneas associadas à ambiente lêntico. Essa pequena variedade de modos reprodutivos é esperada em ambientes não florestados, pois a diversidade de modos reprodutivos é mais um reflexo das características ambientais do que relações filogenéticas (Duellman \& Trueb 1994). Na região estudada, a baixa heterogeneidade ambiental decorrente da paisagem agropastoril e o clima com pronunciada estação seca e imprevisibilidade no mês de início da estação chuvosa (Rossa-Feres \& Jim 2001), são fatores adicionais, que limitam a variedade de micro-hábitats úmidos, necessários para espécies com modos reprodutivos mais especializados. As espécies de Leptodactylidae depositam os ovos em ninhos de espuma na superfície da água, em tocas subterrâneas ou em depressões construídas pelos machos, protegendo-os da dessecação (Downie 1988, Duellman \& Trueb 1994, Prado et al. 2002). Já as espécies de Hylidae são mais susceptíveis a variações no volume de água, pois depositam os ovos em massa gelatinosa submersa ou na superfície da água (Duellman \& Trueb 1994, Arzabe et al. 1998). Assim, esperávamos que o número de Leptodactylidae nas primeiras quinzenas da estação chuvosa fosse maior que o de Hylidae, como registrado por Arzabe et al. (1998) em Santa Luzia do Itanhy, Sergipe. Apesar da desova em ninho de espuma proteger os ovos contra a dessecação (Downie 1988), espécies apresentando modo reprodutivo com desova em massa gelatinosa e girinos na água, considerado o mais generalizado e basal em anuros (Duellman \& Trueb 1994), foram tão comuns no início da estação chuvosa quanto aquelas que desovam em ninhos de espuma. Por outro lado, assim como registrado por Gottsberger \& Gruber (2004), a maioria dos adultos e girinos de Leptodactylidae ocorreu somente, ou apresentou a maior abundância, no início da estação chuvosa, e a maioria dos adultos e girinos das espécies que depositam os ovos em massa gelatinosa diretamente na água, apesar de terem ocorrido no início, apresentaram maior abundância em plena ou no final da estação chuvosa. Isto permite sugerir que espécies que apresentam modo reprodutivo com deposição de ovos em ninhos de espuma são favorecidas em ambientes com flutuações imprevisíveis no nível de água.

Os dez corpos d'água estudados apresentaram uma pequena substituição de espécies, sendo que a elevada diversidade $\beta$ das combinações que incluíram os corpos d’água de água corrente e/ou associados à fragmento de mata ciliar (CA, CM e BP), decorre da baixa riqueza de espécies nestes ambientes, e não de diferenças na composição de espécies. A baixa diversidade $\beta$ encontrada entre os corpos d’água de área aberta, parece refletir um conjunto de adaptações necessárias para a sobrevivência nesses ambientes, já que espécies que ocupam ambientes instáveis ou alterados pelo homem, como os presentemente estudados, tendem a apresentar maior amplitude no uso de recursos (Heyer \& Bellin 1973).
As maiores riqueza e diversidade de espécies foram encontradas em corpos d’água lênticos em área aberta, nos quais indivíduos de um maior número de espécies se reproduziram: as maiores riqueza e diversidade de girinos foram encontradas no açude temporário AT1 e nos permanentes AP2 e AP3. Os menores valores de riqueza e diversidade de espécies foram encontrados nos corpos d’água lóticos em área aberta (CA) e fechada (CM), e no brejo associado a fragmento de mata ciliar (BP). Entretanto, em conseqüência do pequeno número de corpos d’água encontrados em fragmentos de mata na região, não foi possível comparar a ocorrência de anuros em áreas abertas e fechadas. As espécies registradas nesse estudo se enquadram em dois padrões de distribuição geográfica, sensu Duellman (1999): as exclusivamente de formações abertas sul-americanas (complexo caatinga-cerrado-chaco) e as com ampla área de ocorrência, incluindo o domínio atlântico, pampa e caatinga-cerrado-chaco (Basso et al. 1985, Brandão \& Araújo 1998, Duellman 1999, Napoli \& Caramaschi 2000, Colli et al. 2002, Bastos et al. 2003, IUCN 2004). Essa predominância de ocorrência em áreas de formação aberta enfatiza a importância dos corpos d'água lênticos em área aberta para a reprodução dos anuros na região estudada.

Poças e drenagens construídas para favorecer os sistemas agrícolas em hábitats já degradados possibilitam o sucesso reprodutivo de diversas espécies de anuros (Babbitt \& Tanner 2000, presente estudo). Além disso, as adaptações para ambientes de formação aberta da maioria das espécies registradas neste estudo possibilitam sua ocorrência em ambientes construídos pelo homem, como os açudes em áreas de pastagem e de culturas agrícolas presentemente estudados. Como está localizada em área de transição entre os biomas Cerrado e Floresta Estacional Semidecidual Atlântica (Ab’Sáber 2003), não podemos excluir a possibilidade que esta região abrigasse também espécies de formação fechada. Entretanto, não existem estudos nem informações sobre o número e composição de espécies que essa região comportava, antes do desflorestamento ocorrido desde o início do século passado. Apesar do elevado estado de conversão de hábitats, a região noroeste do estado de São Paulo apresenta uma riqueza de anuros relativamente alta, semelhante a localidades onde o grau de conservação ambiental é muito maior (p.ex., Brandão \& Araújo 1998: Estação Ecológica de Água Emendadas, Distrito Federal, região de Cerrado, com 27 espécies de anuros; Bastos et al. 2003: Floresta Nacional de Silvânia, GO, região de Cerrado, com 29 espécies de anuros).

\section{AGRADECIMENTOS}

Os autores agradecem àqueles que sugeriram ou revisaram alguma parte deste estudo: Prof. Dr. Arif Cais, Prof. Dr. Célio F. B. Haddad, Prof. Dra. Lílian Casatti, Prof. Dr. Rogério P. Bastos, Msc. Tiago Gomes dos Santos e aos assessores anônimos da FAPESP referente aos projetos de Iniciação

http://www.biotaneotropica.org.br 
Científica e Mestrado do primeiro autor. Agradecemos também ao Prof. Dr. Francisco Langeani Neto, Prof. Dra. Lílian Casatti e Prof. Dr. Fernando B. Noll pela revisão do Abstract. Este estudo foi financiado pela Fundação de Amparo à Pesquisa do Estado de São Paulo (IC: 01/08675-0; MS: 02/11388-5; BIOTA/FAPESP: 01/13341-3).

\section{REFERÊNCIAS BIBLIOGRÁFICAS}

AB'SABER, A. N. 2003. Os domínios de natureza no Brasil: potencialidades paisagísticas. Ateliê Editorial, São Paulo.

ACHAVAL, F. \& OLMOS, A. 2003. Anfíbios y Reptiles Del Uruguay. Graphis, Impresora, Montevideo.

ARZABE, C. 1999. Reproductive activity patterns of anurans in two different altitudinal sites within the Brazilian Caatinga. Rev. bras. Zool. 16 (3): 851-864.

ARZABE, C., CARVALHO, C. X. \& COSTA, M. A. G. 1998. Anuran Assemblages in Crasto Forest Ponds (Sergipe State, Brazil): Comparative Structure and Calling Activity Patterns. Herpetol. J. 8: 111-113.

AYRES, M., AYRES JR, M., AYRES, D. L. \& SANTOS A. S. 2003. BioEstat 3.0. Aplicações estatísticas nas áreas das ciências biológicas e médicas. Sociedade Civil de Mamirauá, Belém.

BABBITT, K. J. \& TANNER, G. W. 2000. Use of temporary wetlands by anurans in a hydrologically modified landscape. Wetlands. 20 (2): 313-322.

BARCHA, S. F. \& ARID, F. M. 1971. Estudo da evapotranspiração na região norte-ocidental do Estado de São Paulo. Revista de Ciências da Faculdade de Ciências e Letras. (1): 94-122.

BASSO, N. G.; PERI, S. I. \& Di TADA, E. 1985. Revalidacion de Hyla sanborni, Schmidt, 1944 (Anura: Hylidae). Cuad. Herpetol. 1(13): 1-11.

BASTOS, R. P., MOTTA, J.A. O., LIMA, L. P., \& GUIMARÃES, L. D. 2003. Anfíbios da Floresta Nacional de Silvânia, estado de Goiás. Stylo Gráfica e Editora, Goiânia.

BERNARDE, P. S. \& KOKUBUM, M. N. C. 1999. Anurofauna do Município de Guararapes, Estado de São Paulo, Brasil (AMPHIBIA, ANURA). Acta Biol. Leopoldensia. 21: 89-97.

BERNARDE, P. S. \& MACHADO, R. A. 2001. Riqueza de espécies, ambientes de reprodução e temporada de vocalização da anurofauna em Três Barras do Paraná, Brasil (Amphibia: Anura). Cuad. Herpetol. 14(2): 93-104.

BERTOLUCI, J. \& RODRIGUES, J. T. 2002. Seasonal patterns of breeding activity of Atlantic Rainforest anurans at Boracéia, Southeastern Brazil. AmphibiaReptilia. 23: 161-167.

BRANDÃO, R. A. \& ARAÚJO, A. F. B. 1998. A herpetofauna da Estação Ecológica de Águas Emendadas. In Vertebrados da Estação Ecológica de Águas Emendadas. História Natural e Ecologia em um fragmento de cerrado do Brasil Central (J. Marinho-Filho, F. Rodrigues \& M. Guimarães, eds.). SEMATEC/IEMA, Brasília, p. 9-21.
CAIS, A. 1992. Aspectos biológicos e status taxonômico de Hyla biobeba Bokerman \& Sazima, 1973 (Amphibia Anura). Tese de Doutorado. Universidade Estadual Paulista, Rio Claro.

COLLI, G. R., BASTOS, R. P. \&ARAÚJO, A. F. B. 2002. The character and dynamics of the Cerrado herpetofauna. In The Cerrados of Brazil: ecology and natural history of a neotropical savanna (P. S. Oliveira \& R. J. Marquis, eds.). Columbia University Press, New York, p. 223-241.

COLWELL, R. K. 2000. EstimateS: Statistical estimation of species richness and shared species from samples. Version 5. User's guide and application published at: http:/ /viceroy.eeb.unconn.edu/estimates

COLWELL, R. K., CODDINGTON, J.A. 1994. Estimating terrestrial biodiversity through extrapolation. Philos. Trans. R. Soc. Lond. B Biol. Sci. 345:101-118.

CRUMP, M. L. \& SCOTT JR, N. J. 1994. Visual encounter surveys. In Measuring and Monitoring Biological Diversity - Standard Methods for Amphibians (W. R. Heyer, M. A. Donnelly, R. W. McDiarmid, L. A. C. Hayek \& M. S. Foster, eds). Smithsonian Institution Press, Washington, p 84-92.

DONNELLY, M.A. \& GUYER, C. 1994. Patterns of reproduction and habitat use in an assemblage of Neotropical hylid frogs. Oecologia (Heidelb). 98, 291-302.

DOWNIE, J. R. 1988. Functions of the foam in the foamnesting leptodactylid Physalaemus pustulosus. Herpetol. J. 1: 302-307.

DUELLMAN, W. E. 1988. Patterns of species diversity in anuran amphibians in the American Tropics. Ann. MO Bot. Gard. 75: 79-104.

DUELLMAN, W. E. 1999. Distribution Patterns of Amphibians in South America. In Patterns of Distribution of Amphibians (W. E. Duellman, ed.). The Johns Hopkins University Press, Baltimore and London, p. 255-327.

DUELLMAN, W. E. \& TRUEB, L. 1994. Biology of Amphibians. McGraw-Hill, Baltimore and London.

GOOTTSBERGER, B. \& GRUBER, E. 2004. Temporal partitioning of reproductive activity in a neotropical anuran Community. J. Trop. Ecol. 20: 271-280.

HADDAD, C. F. B. 1998. Biodiversidade dos anfíbios no Estado de São Paulo. In Biodiversidade do Estado de São Paulo, Brasil: síntese do conhecimento ao final do século XX. 6: Vertebrados (C. A. Joly \& C. E. M. Bicudo, org.). Editora FAPESP, São Paulo, p. 15-26.

HADDAD, C. F. B. \& SAZIMA, I. 1992. Anfíbios anuros da Serra do Japi. In História Natural da Serra do Japi: Ecologia e Preservação de uma Área Florestal no Sudeste do Brasil (L. P. C. Morellato, org.). Editora da UNICAMP/FAPESP, Campinas, p. 188-211.

HADDAD, C. F. B. \& PRADO, C. P. A. 2005. Reproductive Modes in Frogs and Their Unexpected Diversity in the Atlantic Forest of Brazil. Bioscience, 55 (3): 207 - 217. 
HEYER, W. R. \& BELLIN, M. S. 1973. Ecological notes on five sympatric Leptodactylus (Amphibia, Leptodactylidae) from Ecuador. Herpetologica. 29 (1): 66-72.

IPT, Instituto de Pesquisas Tecnológicas do estado de São Paulo. 2000. Diagnóstico da situação atual dos recursos hídricos e estabelecimento de diretrizes técnicas para a elaboração do plano da Bacia São José dos Dourados Relatório nº 40675 - Minuta. CD Room.

IUCN, Conservation International, and NatureServe. 2004. Global Amphibian Assessment. www.globalamphibians.org. Downloaded on 15 October 2004.

IZECKSOHN, E. \& CARVALHO-E-SILVA, S. P. 2001. Anfíbios do Município do Rio de Janeiro. Editora UFRJ, Rio de Janeiro.

KREBS, C. J. 1999. Ecological Methodology. Addison Wesley Educational Publishers, Menlo Park.

MAGURRAN, A. E. 1988. Ecological Diversity and Its Measurement. Princeton University Press, New Jersey.

MORIN, P. J. 1999. Community Ecology. Blackwell Science, Malden.

NAPOLI, M. F. \& CARAMASCHI, U. 2000. Description and variation of a new Brazilian species of the Hyla rubicundula group. (Anuma, Hylidae). Alytes. 17(3-4): 165-184.

POMBAL JR., J. P. \& GORDO, M. 2004. Anfíbios Anuros da Juréia. In Estação Ecológica Juréia-Itatins. Ambiente Físico, Flora e Fauna (O. A. V. Marques \& W. Duleba, eds.). Holos Editora, Ribeirão Preto, p. 243-256.

PRADO, C. P.A., UETANABARO, M., \& HADAD, C. F. B. 2002. Description of a new reproductive mode in Leptodactylus (Anura, Leptodactylidae), with a review of the reproductive specialization toward terrestriality in the genus. Copeia. 2002 (4): 1128-1133.

PRADO, C. P. A., UETANABARO, M. \& HADAD, C. F. B. 2004. Breeding activity patterns, reproductive modes, and habitat use by anurans (Amphibia) in a seasonal environment in the Pantanal, Brasil. Amphibia-Reptilia. 26, no prelo.

ROHLF, F. L. 1989. NTSYS: Numerical taxonomy and multivariate analysis system. New York, Exeter publishing, version 2.10s.

ROSSA-FERES, D. C. \& JIM, J. 1994. Distribuição sazonal em comunidades de anfíbios anuros na região de Botucatu, São Paulo. Rev. bras. Biol. 54 (2): 323-334.

ROSSA-FERES, D. C. \& JIM, J. 2001. Similaridade no sítio de vocalização em uma comunidade de anfíbios anuros na região noroeste do Estado de São Paulo, Brasil. Ver. bras. Zool. 18 (2): 439-454.

SÃO PAULO. 2000. Atlas das unidades de conservação ambiental do estado de São Paulo. Secretaria do Meio Ambiente, São Paulo.
SBH. 2005. Lista de espécies de anfíbios do Brasil. Sociedade Brasileira de Herpetologia (SBH). Disponível em: http:// www.sbherpetologia.org.br/checklist/anfibios.htm

SOKAL, R. R. \& ROHLF, F. J. 1995. Biometry. W. H. and Freeman, New York.

STRANECK, R., OLMEDO, E. V. \& CARRIZO, G. R. 1993. Catalogo de Vocês de Anfíbios Argentinos, parte 1. L.O.L.A. (Literature of Latin America), Buenos Aires.

TOLEDO, L. F., ZINA, J. \& HADAD, C. F. B. 2003. Distribuição Espacial e Temporal de uma Comunidade de anfíbios Anuros do Município de Rio Claro, São Paulo, Brasil. Holos Environment. 3 (2): 136-149.

TRIOLA, M. F. 1999. Introdução à Estatística. Livros Técnicos e Científicos Editora S. A, Rio de Janeiro.

VIZOTTO, L. D. 1967. Desenvolvimento de anuros da região norte-ocidental do Estado de São Paulo. Tipografia Rio Preto, São José do Rio Preto.

\section{Apêndice 1}

Material testemunho: Hyla albopunctata (DZSJRP 7958), Hyla elianeae (DZSJRP 6420, 6421), Hyla nana (DZSJRP 6416, 6417, 7962, 7963, 8078), Hyla minuta(DZSJRP 6419, 7959), Hyla sanborni (DZSJRP 8072), Phrynohyas venulosa (DZSJRP 7938), Scinax aff. similis (DZSJRP 8070), Leptodactylus chaquensis (DZSJRP 7934-7937), Leptodactylus fuscus (DZSJRP 6411, 6412), Leptodactylus labyrinthicus (DZSJRP 7957), Leptodactylus ocellatus (DZSJRP 6410, 8077), Leptodactylus podicipinus (DZSJRP 6418), Physalaemus centralis (DZSJRP 6413), Physalaemus cuvieri (DZSJRP 6415, 8076), Physalaemus fuscomaculatus (DZSJRP 8067), Physalaemus nattereri (DZSJRP 8068), Pseudopaludicola aff. saltica (DZSJRP 7960, 7961), Elachistocleis sp. (DZSJRP 6424, 6425).

Título: Diversidade, distribuição espacial e temporal de anfíbios anuros (Amphibia, Anura) na região noroeste do estado de São Paulo, Brasil

Autores: Tiago da Silveira Vasconcelos, Denise de C. Rossa-Feres

Biota Neotropica, Vol. 5 ( número 2): 2005

http://www.biotaneotropica.org.br/v5n2/pt/ abstract?article+BN01705022005

Recebido em 10/03/2005 - Revisado em 04/05/05 Publicado em 03/08/05

ISSN 1676-0603 